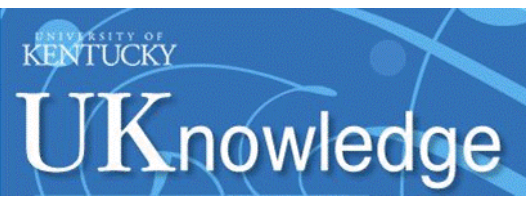

University of Kentucky

UKnowledge

7-2008

\title{
Medical Supervision of Young Female Athletes Training in Complex Coordinational Sports
}

Irina Schevchenko

Dnepropetrovsk Medical Institute of Folk Medicine, Ukraine

Viktor V. Abramov

Dnepropetrovsk Medical Institute of Folk Medicine, Ukraine

Paul T Gibson

Southern Illinois University, Carbondale

Hatim A. Omar

University of Kentucky, hatim.omar@uky.edu

Follow this and additional works at: https://uknowledge.uky.edu/pediatrics_facpub

Part of the Pediatrics Commons

Right click to open a feedback form in a new tab to let us know how this document benefits you.

\section{Repository Citation}

Schevchenko, Irina; Abramov, Viktor V.; Gibson, Paul T; and Omar, Hatim A., "Medical Supervision of Young Female Athletes Training in Complex Coordinational Sports" (2008). Pediatrics Faculty Publications. 79. https://uknowledge.uky.edu/pediatrics_facpub/79

This Article is brought to you for free and open access by the Pediatrics at UKnowledge. It has been accepted for inclusion in Pediatrics Faculty Publications by an authorized administrator of UKnowledge. For more information, please contact UKnowledge@lsv.uky.edu. 


\section{Medical Supervision of Young Female Athletes Training in Complex Coordinational Sports}

\section{Digital Object Identifier (DOI)}

http://dx.doi.org/10.1515/IJAMH.2008.20.3.343

\section{Notes/Citation Information}

Published in International Journal of Adolescent Medicine and Health, v. 20, no. 3, p. 343-351.

(C) Freund Publishing House Ltd.

The copyright holder has granted permission for posting the article here. 


\title{
Medical supervision of young female athletes training in complex coordinational sports
}

\author{
Irina Schevchenko, $\mathrm{MD}^{1}$, Viktor $\mathrm{V}$ Abramov, $\mathrm{MD}^{1}$, Paul $\mathrm{T}$ Gibson, $\mathrm{PhD}^{2}$ and \\ Hatim A Omar, MD, FAAP \\ 'Dnepropetrovsk Medical Institute of Folk Medicine, Dnepropetrovsk, Ukraine, ${ }^{2}$ Department of \\ Plant, Soil and General Agriculture, Southern Illinois University, Carbondale, United States \\ and ${ }^{3}$ Division of Adolescent Medicine, Department of Pediatrics, University of Kentucky \\ College of Medicine, Lexington, United States of America
}

\begin{abstract}
This article proposes simple medical criteria that can be used by trainers and others for effective medical supervision of young female athletes. METHODS: The cross-sectional, agestratified study compared girls 10-17 years of age involved in intensive training in gymnastic floor exercises, trampoline, or badminton. Each sport and/or control group was represented by $\mathbf{4 0 - 4 5}$ girls. Data included medical history, morphometric variables and abservation of biological development. RESULTS: Gymnasts started training earliest ( 25 years old) and trained most intensely $(18-20 \mathrm{~h} / \mathrm{wk})$, followed by trampolinists and then badmintonists. Height, weight, body mass index, and \% body fat were reduced in athletes, with gymnasts showing the greatest reduction. Athletes showed higher ratios of leg length to height and shoulder width/hip width, and smaller pelvic size compared to height. The average age of menarche of gymnasts was 13.8 (1.6 year later than controls). Delays of biological development of more than 2 years were common in athletes, and some gymnasts showed more than a 4-year delay. These delays were related to morphometric indicators of hormonal imbalance and to low body fat. Gymnasts had more childhood diseases, with an infection index of 2.8 compared to 1.1 for the control group, and had a higher level of chronic ENT problems. CONCLUSIONS: Trainers need to protect the health of athletes. During the course of training, anamneses, delayed menarche and other signs of delayed biological development must be monitored. Morphometric measures and indicators of biological development are proposed to provide simple criteria important in protecting the athletes' health.
\end{abstract}

Keywords: complex coordinational sports, hormonal imbalance, biological development, physical development, morphometric

Comespondence: Hatim Omar, MD, FAAP, Professor of Pediatrics and Obstetrics/Gynecology, Chief, Adolescent Medicine \& Young Parent programs, J422, Kentucky Clinic, University of Kentucky, Lexington, KY 40536 United States. Tel. 859-323-6426 ext. 311; Fax. 859-257-7706; Email: haomar2@uky.edu

Submitted: January 01, 2008. Revised: April 07, 2008. Accepted:.April 27, 2008.

\section{INTRODUCTION}

Issues in women's athletic training continue to become more important each year. Modern training of athletes is characterized by specializing at a younger age, training for more hours, and involving more intense physical strain in training and competition. This intensity affects the morphometric 
parameters of physical development and the rate of biological development of young athletes. According to ( 1 and 2), a disturbance of reproductive functions occurs more frequently in athletes than in the general population. One problem is that often health of the athletes is not considered a priority (3). The scientific literature documents that both physical and biological development is delayed by the physical strain on young athletes (4). Considering that the preparation of competitive athletes occurs in stages (basic training, training for the specific sport, and becoming highly competitive), it becomes obvious that the basic period of training includes many hours of intensive physical stress at the time when puberty occurs. This period is also characterized by major physical changes and sensitivity to the surrounding conditions. The data of Abramov et al (5) showed that systematic athletic training, independent of the specific training process, is related to developmental delays in young women athletes. Hormonal imbalances, especially hypo-estrogenemia and hyper-androgenemia, were evident and related to the developmental delay (5).

Monitoring the actual hormonal levels of athletes is difficult, expensive, and not realistic for athletic trainers in many situations. Therefore, it is important to identify simple indicators of hormonal imbalance in young women athletes. Morphometric ratios and simply observed indicators of biological development may be suitable for this purpose. The identification of appropriate indicators will allow modification of the training process and rational medical supervision of athletes for the purpose of preventing pathological disturbances of their development and reproductive function. The purpose of this study was to identify simple medical criteria that can be used by trainers, sports medicine practitioners, and others for the purpose of effective medical supervision of young female athletes participating in nonrepetitive, complex coordinational sports.

\section{METHODS}

The research reported here was a crosssectional study (6) that included 130 young female athletes between ages 10 and $17 \mathrm{y}$ participating in three different acyclical, complex, coordinational sports: gymnastic floor exercises $(n=45)$, badminton $(n=$ $40)$, and trampoline $(n=45)$. The sample for each sport was provided by six trainers in sports schools in Dnepropetrovsk, Ukraine, who agreed to cooperate with this research. The sampling occurred over the period of 2002-2007, with all data for an individual girl collected at one time. The extended period of sampling was required because the measurement of each girl was time-intensive (only a part of the data is reported here). The control group $(n=45)$ consisted of a random sample of girls of the same age during the same period (20022007) who participated in ordinary, mandatory physical education classes in ordinary schools in Dnepropetrovsk. Both the control group and the three athletic groups were stratified by age, with each having 10 14 girls per age-subgroup [10-11, 12-13, $14-15,16-17$ years of age].

\section{Medical history}

In Ukraine, all citizens, including children, have a permanent card in which medical observations are recorded. Children attending a sports school receive a medical evaluation twice a year, whereas others visit a physician when necessary for medical care or for meeting school requirements, etc. The medical records were supplemented by a questionnaire that included information about parents and child. Parental information included general health, course of 
pregnancy and birth, length and weight of the child at birth, course of infancy and early childhood, childhood diseases, etc.

\section{Clinical observations}

Each girl in the study was observed by an ENT specialist, an ophthalmologist, an endocrinologist and a gynecologist.

\section{Physical measurements}

Data recorded included body weight, height, leg length (to vertilnoi point), shoulder width (acromion), and four pelvic measurements (width at the spinarum, cristarum, and trochanter, and frontal-basal thickness from the symphysis to the $5^{\text {th }}$ lumbar vertebrae). The following ratios were calculated: leg length/height, shoulder width/hip width, pelvic index (sum of the four pelvic measurements/height), and body mass index $\left(\mathrm{BMI}=\right.$ weight $\left./(\text { height })^{2}\right)(7)$. The first three of these ratios were summarized into ranges defined by Abramov (8). Ratios outside of the normal range are suggestive of hormonal imbalance.

Percent body fat was determined by caliper measurements of skin thickness (9). Biological development was evaluated by underarm hair, pubic hair, breast development, and age at menarche. Compared with normal values, a delay of 2.0 to 2.9 y was considered Stage 1 delay. Stage II and Stage III involved delays of 3.0 to $3.9 \mathrm{y}$ and $\geq 4.0$ $y$, respectively $(10)$. The date of first menstruation and the regularity, cycle length, and days of bleeding were recorded.

\section{Statistical analysis}

Morphometric data were analyzed using regression against age. Group means were compared, assuming a common linear slope on age for all groups, by F-protected LSD $(\alpha=0.05)$, based on residual error. Parallelism of group slopes, and quadratic regressions for specific groups were tested by an F-test of the reduction in error sums of squares. When non-parallel slopes or quadratic regression was present, fitted group means at the average age of all subjects (including controls) were compared by pairwise $t$-tests based on the appropriate error for each treatment. The effect of sports training on body characteristics (shoulder/hip ratio, etc.) was also evaluated by the percentage of girls having specific ranges of values within specific age categories.

For those variables that were not regressed against age (age at beginning of training, stage of biological development, infection index, etc.), standard analysis of variance and LSD comparisons were used.

\section{RESULTS}

Table 1 shows morphometric measurements. Height and weight were lower in athletes than in the control group. Gymnasts had the lowest height and weight, followed by trampolinists and then badmintonists. Height and weight increased equally per year in all groups. BMl followed the same pattern as height and weight, except that no significant difference was found between trampolinists and badmintonists.

The percent body fat was lowest in gymnasts, followed by trampolinists and then badmintonists. Body fat consistently increased with age in the control group ( $b=$ $0.8 / y$ ). In contrast, body fat $\%$ decreased with age in gymnasts and badmintonists $(b=-0.3 / y$, highly significant) and trampolinists $(b=-0.5 / y$, highly significant $)$, even though gymnasts already had low body fat even at age $10(\sim 17 \%)$. By age $17 \mathrm{y}$, the mean of each athletic group was $17 \%$ or less, whereas the control group was $>24 \%$.

The ratio of shoulder width to hip width was higher in gymnasts than in any other group. In all groups, this ratio decreased slightly with age. The ratio of leg length to height was higher among athletes than in 
Table 1. Morphometric measurements

\begin{tabular}{|c|c|c|c|c|c|c|c|}
\hline \multirow{2}{*}{$\begin{array}{l}\text { All groups } \\
\text { Mean }\end{array}$} & $\begin{array}{l}\text { Height } \\
\text { Mean }\end{array}$ & $\begin{array}{l}\text { Weight } \\
\text { Mean }\end{array}$ & BMI & $\begin{array}{c}\% \text { body } \\
\text { fat }\end{array}$ & $\begin{array}{l}\text { Shoulder } \\
\text { Hip ratio }\end{array}$ & LegL $/ \mathrm{Ht}$ & $\begin{array}{l}\text { Pelvic } \\
\text { Index }\end{array}$ \\
\hline & 153.3 & 42.3 & 17.8 & 17.9 & 1.28 & 57.3 & 57.8 \\
\hline Pooled Slope & $3.35^{+\infty t+}$ & $2.9^{n+m}$ & $0.48^{n+t}$ & $-0.06^{\text {n+m }}$ & $-0.02^{n+t}$ & $0.29^{*+*}$ & $0.60^{* t+t}$ \\
\hline diff in slope & ns & ns & ns & ns & ns & ns & ns \\
\hline \multicolumn{8}{|l|}{ Group Means } \\
\hline$C(n=45)$ & $158.6 \mathrm{a}$ & $48.9 \mathrm{a}$ & $19.3 \mathrm{a}$ & $21.2 \mathrm{a}$ & $1.23 \mathrm{a}$ & $54.2 \mathrm{a}$ & $60.0 \mathrm{a}$ \\
\hline$B(n=40)$ & $155.0 \mathrm{~b}$ & $43.2 \mathrm{~b}$ & $17.9 \mathrm{~b}$ & $17.3 \mathrm{~b}$ & $1.26 \mathrm{~b}$ & $57.6 \mathrm{~b}$ & $58.2 \mathrm{~b}$ \\
\hline$T(n=45)$ & $151.2 \mathrm{C}$ & $40.7 \mathrm{c}$ & $17.7 \mathrm{~b}$ & $17.7 \mathrm{~b}$ & $1.25 \mathrm{ab}$ & $58.4 \mathrm{c}$ & $58.5 \mathrm{~b}$ \\
\hline$G(n=45)$ & $149.0 \mathrm{~d}$ & $36.8 \mathrm{~d}$ & $16.3 c$ & $15.5 \mathrm{C}$ & $1.36 \mathrm{c}$ & $59.1 \mathrm{c}$ & $54.6 \mathrm{c}$ \\
\hline $\begin{array}{l}\text { MS error } \\
\text { (164-168 df) }\end{array}$ & 18.8 & 18.8 & 2.12 & 2.67 & 0.0041 & 2.81 & 6.64 \\
\hline $\begin{array}{l}\text { LSD } 0.05 \\
\text { Group Means }\end{array}$ & 1.88 & 1.88 & 0.63 & 0.71 & 0.028 & 0.73 & 1.12 \\
\hline
\end{tabular}

$*{ }^{* *}, * *$ Statistically significant at $P<.05,<.01$, and $<.001$, respectively

the control group, especially in gymnasts and trampolinists. This ratio increased with age more strongly in the control $(b=0.86)$ than in the athletic groups $(b=0.28$ to 0.67 ). The pelvic index was lower among athletes than in the control group, especially in gymnasts. This ratio increased with age in all groups.

Table 2 shows indicators of hormonal imbalance. According to V. Abramov (5, 8 ), ratios of leg length/height $>61.8$ are a strong indicator of hypo-estrogenemia, and ratios $>55.5$ are often associated with such imbalance. Gymnasts showed the highest ratios, with $85 \%$ above 55.5 , even at age $10.11 \mathrm{y}$, and $100 \%$ above this level from age $12-13$ y onward. From $10 \%$ to $27 \%$ were above 61.8 , a strong indirect indicator of hypo-estrogenemia for some of the gymnasts in each age group. Both trampolinists and badmintonists showed ratios higher than the control group, indicating some occurrence of hypo-estrogenemia in these groups as well.
Strong evidence of hypo-estrogenemia (S/H ratio > 1.47 ) was shown only in gymnasts (14\% to $18 \%$ ) in the younger two age groups, but a substantial percentage had ratios $>1.35$, suggestive of some degree of hypo-estrogenemia. A few trampolinists had high ratios as well. The high ratios reflected larger shoulder width and smaller hip width in athletes than in the control.

Pelvic indices $<55$ indirectly suggest hormonal imbalance, especially if $<50$. Low pelvic indices were most frequent in gymnasts. A number of trampolinists showed ratios low enough for concern, even though the mean ratio of trampolinists was statistically not less than the control (Table 1).

Body fat $<17 \%$ by the expected age of menarche is considered a serious impediment to normal biological development (11). Body fat $>20 \%$ is typical at menarche, and normally continues to increase throughout adolescence $(8,11)$. On average, menarche 
Table 2. Me xsurements related to hormonal imbalance

\begin{tabular}{|c|c|c|c|c|c|c|c|c|c|c|c|c|c|c|c|}
\hline Group & Age & $>20$ & $18.5-20$ & $17-18.5$ & $<17$ & $555-6 \% 7$ & $61.8-688$ & $1.35-1.44$ & $1.45-1.53$ & $553-603$ & $50.1-55.2$ & $47.6-50$ & $2-3 y$ & $3-4 y$ & $>$ 事 \\
\hline \multirow{2}{*}{$C$} & $12-13$ & 41.7 & 41.7 & 16.6 & & 40 & & & & 70 & & & & & \\
\hline & $14-15$ & 72.7 & 27.3 & & & 63.6 & & & & 36.4 & 45.5 & & & & \\
\hline \multirow[t]{3}{*}{ B } & $10-11$ & 10 & 50 & 10 & 20 & 60 & & & & 60 & 40 & & \multicolumn{3}{|c|}{ Age of Menarche $=129$} \\
\hline & $12-13$ & 10 & 20 & 20 & 50 & 60 & 30 & & & 80 & 10 & & $\$ 0$ & & \\
\hline & $14-15$ & 10 & 10 & 10 & 0 & 80 & & & & $\$ 00$ & & & 20 & & \\
\hline \multirow{2}{*}{$T$} & $14-15$ & & 16.6 & 41.7 & 41.7 & 87.5 & 12.5 & 17 & & 63.6 & & & 33 & 8 & \\
\hline & $16-17$ & & & 9.8 & 90.9 & 90.9 & 9.1 & & & 14.3 & 57.2 & 28.5 & 46 & 8 & \\
\hline \multirow[t]{4}{*}{ G } & $10-11$ & 7.1 & 3.1 & 35.8 & 50 & 64.3 & 21.4 & 36 & 14 & 45.5 & 36.3 & 18.2 & \multicolumn{3}{|c|}{ Age of wenarche $=138$} \\
\hline & $12-13$ & & 7.1 & 3. & 81.8 & 22. & 27.3 & $2 \%$ & 18 & 80 & 20 & & $2 ?$ & 9 & \\
\hline & $14-15$ & & & & 100 & 90 & 0 & 30 & & 30 & 30 & & 36 & 88 & \\
\hline & $16-17$ & & & & 100 & 30 & 20 & 20 & & & & & 18 & 29 & 16 \\
\hline
\end{tabular}


Table 3. Percentage of girls with disturbed menstrual cycles, $\%$

\begin{tabular}{|l|c|c|c|c|c|c|}
\hline \multirow{2}{*}{ Menstrual cycle in days } & \multicolumn{3}{|c|}{1 y post menarche } & \multicolumn{3}{|c|}{2 y post menarche } \\
\cline { 2 - 7 } & $\mathrm{B}$ & $\mathrm{T}$ & $\mathrm{G}$ & $\mathrm{B}$ & $\mathrm{T}$ & $\mathrm{G}$ \\
\hline$>35 \mathrm{~d}$ (oligomenorrhea) & & 8 & 21 & & & 9 \\
\hline$>6 \mathrm{~d}$ (polymenorrhea) & & 8 & 32 & & & 17 \\
\hline$<21 \mathrm{~d}$ (hypermenorrhea) & & & & 17 & 15 & 18 \\
\hline
\end{tabular}

B, badmintonists; T, trampolinists; G, gymnasts

Table 4. Risk factors for athlete health

\begin{tabular}{|c|c|c|c|c|c|c|c|c|}
\hline \multirow[b]{2}{*}{ Group } & \multirow[b]{2}{*}{$\mathbf{N}$} & \multirow{2}{*}{$\begin{array}{l}\text { Age training } \\
\text { began }(y)\end{array}$} & \multirow{2}{*}{$\begin{array}{l}\text { Hours of } \\
\text { traininghwk }\end{array}$} & \multirow{2}{*}{$\begin{array}{l}\text { Infection. } \\
\text { Index }\end{array}$} & \multicolumn{4}{|c|}{$\%$ with chronic ENT problems } \\
\hline & & & & & tonsillitis & sinusitis & $\begin{array}{c}\text { adenoid } \\
\text { II, III }\end{array}$ & tota \\
\hline $\mathrm{C}$ & 45 & - & - & 1.1 & 30 & 7 & 7 & 44 \\
\hline B & 40 & 9.1 & $8-10$ & 1.4 & 30 & 5 & 8 & 43 \\
\hline$T$ & 45 & 6.2 & $10-12$ & 1.9 & 31 & 16 & 7 & 54 \\
\hline$G$ & 45 & 4.6 & $18-20$ & 2.8 & 53 & 4 & 9 & 66 \\
\hline
\end{tabular}

occurs before age 12-13 y in non-athletes (12), and did so in most of the control group. At age 12-13 y, the control group averaged about $20 \%$ body fat, with all girls $>17 \%$. At this age, $50 \%$ of badmintonists, $20 \%$ of trampolinists, and $82 \%$ of gymnasts had $<17 \%$ body fat. By age $16-17 \mathrm{y}$, all girls in the control group had body fat $>20 \%$, but none of the athletes were above $20 \%$. Body fat $<17 \%$ was found in $100 \%$ of gymnasts, $91 \%$ of trampolinists, and $40 \%$ of badmintonists. Body fat levels in these athletes were definitely lower than that considered necessary for normal biological development.

The age of menarche, as one measure of biological development, was $1.5 \mathrm{y}$ later in gymnasts than in the control group. Athletes participating in trampoline and badminton also had delayed menarche, but not as severely as gymnasts. All three groups of athletes included a number of girls with puberty delayed more than $2 \mathrm{y}$, and delay was more evident as age increased. Especially serious delays were observed among gymnasts, with $16 \%$ delayed more than $4 \mathrm{y}$ when compared with normal, and $63 \%$ showing delays of at least $2 y$.

Menstrual cycle disturbances are shown in table 3. Oligomenorrhea was observed in one or more girls in trampoline and gymnastics $1 \mathrm{y}$ after menarche and in gymnasts 2 y after menarche. The same pattern occurred for polymenorrhea. Hypermenorrhea occurred in all three groups of athletes $2 \mathrm{y}$ after menarche.

Some factors that potentially contribute to delayed biological development are shown in table 4. The familial history of the athletes showed that mothers who had trained in sports had experienced delayed menarche as well. Gymnasts had a higher percentage of mothers who had trained and mothers with later menarche than other 
Table 5. Recommended criteria for morphometric evaluation of young female athletes

\begin{tabular}{|l|c|c|c|}
\hline \multirow{2}{*}{ Criteria } & \multicolumn{2}{|c|}{ Nomal } & $\begin{array}{c}\text { Indicator of hormonal } \\
\text { imbalance }\end{array}$ \\
\cline { 2 - 4 } & before menarche & after menarche & Higher ratio \\
\hline LegLheight ratio $(x 100)$ & $49-52$ & $56-62$ & Higher ratio \\
\hline Shoulderhip ratio & $<1.35$ & $<1.25$ & Lower index \\
\hline Pelvicheight index & $55-60$ & $60-63$ & Lower value \\
\hline$\%$ body fat & $>17$ & $>20$ & \\
\hline
\end{tabular}

groups of athletes. Gymnasts started training very early $(4.6 \mathrm{y})$ and had very intensive training (18-20 h/wk). Gymnasts also experienced more childhood diseases than other groups (almost 3 times the number in the control group). Abramov (8) and others (13) noted even more frequent occurrence of childhood diseases in athletes (infection index $>4$ ). Chronic sub-acute tonsillitis was noted in over half of the gymnasts. There may have been a higher frequency of chronic sinusitis in trampolinists, but a larger sample would be needed to verify this finding.

\section{DISCUSSION}

Morphometric ratios, such as $\mathrm{S} / \mathrm{H}, \mathrm{LL} / \mathrm{H}$, and pelvic index/height have been shown to be related to measured hormonal imbalance and delayed biological development in young women in other sports, including basketball, volleyball, and track and field $(5,8)$. The similar altered ratios and delayed biological development observed in the present study can be taken as evidence of hormonal imbalance.

Percent body fat in the control group at age $16-17$ y ranged from $22.85-27.2$, with an average of 24.7 percent. The absence of very high values is consistent with the finding that most Ukrainian girls are trim (12). Even compared with the relatively trim control group, the percent body fat in athletes was strongly reduced by training, to levels markedly below those needed for normal biological development. Other research shows that body fat percent should be above $17 \%$ to avoid delaying menarche (14). For a regular menstrual cycle, the body fat should be more than $20 \%$ to $22 \%$ (15-16), or even $>24 \%$ (1). The levels found here were so low that future fertility is likely to be reduced $(8,11,13)$. Biological development was delayed in a large percentage of the athletes. Delays of more than $4 \mathrm{y}$ occurred in some of the gymnasts. In general, the degree of mor-phometric alteration and delay of biological development corresponded with the start of training at earlier ages and with the intensity of the training.

Although trainers obviously must emphasize obtaining maximum performance of their athletes, trainers should not endanger the present and future health of the athletes they train. The athletes in this study experienced a higher number of childhood diseases than the control group, and higher levels of chronic ENT problems. Adverse effects on the future health of the athletes is also anticipated, partly in relation to excessively low body fat $\%$ and the delay in biological development. Trainers must consider indicators of risk and evidence of delayed physical and biological development when accepting girls for training and monitor these indicators throughout the course of training. 
Caution should be used when dealing with girls with a childhood disease infection index $>3$ and indicators of chronic ENT problems. During the course of training, history of delayed menarche and other signs of delayed biological development must be monitored, and if severe, the training regime must be lightened or interrupted. Delays of 2-3 y in biological development should result in reduced intensity of training, and girls with delays of more than $3 \mathrm{y}$ should be evaluated by an endocrinologist and gynecologist or an adolescent medicine specialist to determine if training can continue without permanent harm. Morphometric indicators of hormonal imbalance (see table 5) should be monitored, and considered a possible precursor to significant delays in biological development.

\section{ACKNOWLEDGMENTS}

The lead author wishes to thank Diana Constantinovna Rukavishnikova for encouragement to undertake this study and providing indispensable guidance.

\section{REFERENCES}

1. Shahlina L, Futorniy S. Health of athletes-an issue of modern sports medicine. J Sports Medicine 2003;1: 5-12. [Natl Univ Phys Educ Sport, Kiev, Ukraine, in Russian]

2. Bachinska NV. Planning the training intensity of the pre-competition period for acrobatic pairs considering the biological characteristics of females. Dissertation. 2006. [Kiev State Inst Phys Educ Sport, in Ukrainian, Engl summary] Unpublished.

3. Niauriy DA, Yevdokımova FA, Sazikina El, et al. Reproductive health of women athletes. Methodological Bull 2003:28. [Sci Literature Publ, St
Petersburg, in Russian]

4. Soboleva T, Sobolev D, Chernuhina O, et al. Issues in women's Sports. J Sports Medicine 2004;1-2:11-20. [Russian]

5. Abramov V, Smirnova E, Abramov S. Functional state of the endocrine system in athletes during puberty. J Sports Med 2004;1-2:21-8. [Russian]

6. Shevchenko IM. Medical supervision of athletes in complex coordinational sports. Dissertation. 2007. [Dnepropetrovsk Med Acad, in Ukrainian, Engl summary] Unpublished.

7. Frank J. Cerny, Harold W. Burton. Exerc Physiol Health Care Professionals 2001;1:383.

8. Abramov VV. Functional state of endocrine and cardiopulmonary systems of athletes during puberty. Dissertation. 1992. [Pavlova Med Inst, St Petersburg, in Russian, Engl summary] Unpublished.

9. Assessment of the physical development of students in institutions of higher education. Methodological Recommend 1981:17. [Dnepropetrovsk Natl Univ, in Russian]

10. Le venetz SA, Kulikova LF, Plehova El, Rubina LA. Medical examination of adolescent females with delayed biological development. Methodological Recommend 1988:23. [National Res Inst Children Adolesc, Kharkov, Ukraine, in Russian]

11. Sha hlina L, Povoroznuk V. Triad of women athletes: Facts for and against. J Sports Med 2004;1-2:29-39. [Russian]

12. Barilyak IR, Polka NS. Physical development of children of different regions of Ukraine. Ternopil: Ukrainian Med Book Publ, 2000:208. [Ukrainian]

13. Dukach LM. Relationship of intensive training in uark and field with height and development of young women athletes during puberty. J Medical Perspect 1997; 
2(2):79-81. [Dnepropetrovsk Med Acad, Ukraine, in Ukrainian]

14. Abdul kadirova ZK, Baldin AB. Relationship of body mass with reproductive function in women. $2^{\text {ad }}$ Int Congr Sport and Health, 2005: 5-6. [Russian]

15. B ogdanova EA. Gynocology of children and adolescents. Med Inform Agency 2000:330. [Russian]

16. Zirano va EA. Disturbances of the reproductive system of athletes. Proc $5^{\text {th }}$ Int Sci Conf Students Young Sci, Current issues in sports medicine, physical education, physiotherapy, 2006:20. [Russian] 